\title{
The Role of Student Organizations in the Freshman Adaptability Education
}

\author{
Kun Jiao, Fei Yang \\ The Communist Youth League,Agricultural University Of Hebei,Baoding,China
}

\begin{abstract}
At present, in colleges and universities have the adaptability of freshmen in education. On the one hand, is a new entrance in order to help students improve the ability to adapt to the environment, quickly into the new learning at the university of life. On the other hand, it is an important means of implementing ideological and political education of the school. As student autonomous organization under the guidance in school, through a variety of activities, student community has played an important role in construction of peer education atmosphere, helping them to better adapt to the school environment.
\end{abstract}

Keywords: Community; Freshman; Adaptive education

\section{INTRODUCTION}

Since the 21 st century, with the depth of China's reform and opening degree, the huge changes in social each aspect, the current our country society has deep into the reform period, various aspects contradictions are highlighted. Student groups in step into a new social environment, especially the college students from high school to college. In the face of the change of the learning method, the change of learning environment, and the current situation related to social employment pressure, appear easily don't adapt to school life. Influenced students are slightly for a period of time study life, severe cases may lead to psychological problems of students, and even suicidal malignant events, etc. Therefore, in the context of the current society, adaptability of freshmen in education is particularly important. Student associations are mass organizations of community. It organized by the students play an important role in the life when a freshman admission will recruit new admission, to help freshmen adapt to the learning environment, quickly step into the new environment.

\section{2. "Adaptive" and "students"}

"Adaptability refers to the individual effectively respond to and comply with the natural and social environment. Including the individual independent life, maintain their own life, meet the demands of the individual and society proposed culture"[1]. We often say that for the adaptability of freshmen education, refers to in order to make the new entrance of college freshmen adapt to the school environment and the process of special education activities, including special psychological counseling, seminar etc. Questions about the "fitness", the Dutch scholar from learning as early as the eighty s of the 20th century, social, emotional, adapt to and dependent on schools four aspects to assess college students' adaptability problems.Mr Wenzel and Asher from achievement motivation, self-control, academic performance, relationship between teachers and students of evaluation of young students from the aspects such as academic adjustment; Berndt point out, bad relationships may lead to students' school adjustment difficulties. $^{\text {[2] }}$

"college student associations are college students according to their own interests and hobbies, spontaneously organized to rich after school life, increase knowledge, edify sentiment, for the purpose of self management, self education", self service mass groups." ${ }^{,[3]}$ College freshmen had just experienced a strain of the college entrance examination into the university, they face from high school to college students the role transformation. Whether in study or in life are very different from the condition of the high school. They for the campus full of curiosity, also hopes to participate in some activities quickly into the school life. Most student community management by the students themselves. Each year freshmen admission after facing a freshman recruiting, this is an important means of possible the continuation of a community, as well as each created the acceptance of the new environment, which new stage to show themselves.

\section{A freshman adaptability problems of education now}

\subsection{The main performance of the freshmen adapt to the problem}

\subsubsection{Don't adapt in learning}

It is a freshman of adaptive performance in the most obvious part of the problem that they does not adapt learning. Accustomed to high school, there are strict schedules, learning arrangement is very compact, coupled with the college entrance examination after many classmates put down the psychological burden, after entering the university suddenly feel without the learning objectives, learning motivation as well as original enough. According to tencent Michael thought level 2010 college freshmen monthly tracking attune Chad, according to the results of " $61 \%$ of undergraduates think main problem is the study of the problems after the entrance, first among learning problems in the lack of learning motivation". 
There are more boys than girls, and easy to learning problems, 62\% and 58\% respectively", ${ }^{[4]}$ Second university teachers' teaching is different from middle school, not too detailed combing textbook knowledge, more is the premise of building a framework, through achieving the students read more books for book knowledge to master. Many students get accustomed to passive learning in high school, will don't know what to do in the university class. Finally, in terms of curriculum than high school at the University of Very Loose, Students have a lot of free time but don't know how to arrange and study. All three reasons, at the beginning of many freshmen in school because of the lack of learning goal and motivation, Internet addiction easily lead to learning are falling behind, and then into a vicious circle.

\subsubsection{Don't fit in terms of life}

Freshmen don't adapt to the life, performance ability and specific living environment in life. First of all, most of the current university students after 90, since the childhood living conditions is relatively superior, parents meticulous care, especially for high school students no boarding experience, three years of high school life. Many aspects are meticulously cared for by parents, suddenly into the campus need to provide for oneself, it shows a lot of not adapt. Including won't wash his clothes, and don't know how to tidy up dormitory life such as small problems. We often see some freshmen can not find the dining room and accumulate wash dirty socks home such as news, this just shows many freshmen have some problems in terms of the ability of life. The second project is home to for school climate differences, eating habits, and don't adapt to the schedules, etc.). Many college students are out-of-town, especially students across the north-south border, in the face of the local climate, diet and other problems easy to appear problem, cause its adaptability in other ways.

\subsubsection{Do not adapt to the interpersonal relationships}

After entering the university, each college freshmen face above all is a group of strange classmates and teachers, for few of the more introverted students' personality, to adapt to the unfamiliar environment might be a little difficult. Some freshmen because some little problems in life are difficult to be in a group, to produce the feeling of loneliness; or because some conflicts caused tensions, relationships with classmates influence further communication with classmates; or confused in with the opposite sex; or had trouble with relationships clumps. These could cause a freshman adaptability problems, unable to accept the school environment, even more serious psychological problems, affects normal school life.

\subsection{The problems existing in the Freshmen adaptive education}

\subsubsection{Education content is too simple}

In many colleges and universities don't really have a special "fitness education" courses. Only when the start of the freshman, through the opening ceremony, or a general meeting of the freshmen education, preaching culture or some school rules and regulations, guiding students to understand the new university life, can be achieved in many aspects, such as study, life and interpersonal transformation. But on the content are the same. Has a history school, school conditions, and professional introduction and so on. These contents are the same, simple. For freshmen from the college entrance examination only, is not able to make it into the heart to realize adaptive all aspects of education, timely discover and solve their own problems in the process of to adapt to the new environment.

\subsubsection{Education form a single, cannot attract students}

"At present, the adaptability for college freshmen education mainly lectures, visit the practice is complementary, with a small amount of one-on-one tutoring form of education." [5] lectures refers to the opening ceremony or freshman class meeting, etc., the relevant person in charge of by the school or the teacher in charge for new a form of one-way transmission of knowledge. Visiting practice is guides the student to visit the learning history, mostly on a brief introduction to the school situation, help students better understand and accept the school. One-to-one tutoring is through specialized counseling center or counselors to achieve targeted conversations, this kind of education is less, and didn't really play the role of education in advance. Because practice is often a student adaptability problems, counselors know it intervenes in a timely manner to adjust. Although with the development of current science and technology, micro letter platform, QQ, Weibo and so on can be a new adaptive education to carry out the way, but the traditional theory still occupies the dominant position. Through the practice of experiential education is too little, lack of necessary communication equality.

\subsubsection{Education time is shorter, not long-term influence}

According to the questionnaire survey was conducted among 2010 freshmen in 7 universities in Chongqing”. The results show that the adaptability education for over a month of $41.07 \%$, two months of up to $6.93 \%$, and more than two months is only 1. 3\%". ${ }^{[6]}$ This suggests that in colleges and universities to carry out the freshmen adapt to 
education, most of them are in the time of school activities more rich content, as time goes on this part of the gradually faded. But college students' adaptability is internalized into the externalization of a process performance. The internalization is the foundation, and is particularly important, and it is a long process of development, if the simple education by relying on nothing more than a week or a month just to realize the new adaptive education has achieved good obviously is not realistic. Because the relevant after the freshman education, the students began to truly devoted to study and life. This time they began their real face because of some problems caused by lack of adaptability, may said some of the original theory at this time no use. This requires our adaptability education must be along with the continuously go deep into students' learning life forever.

\section{The characteristics of the students and the role in the new adaptive education.}

\subsection{The characteristics of Student Associations}

"College students' social organizations is the college students in order to common hobbies, interests or common responsibility voluntarily, spontaneously organized student mass organization" ${ }^{[7]}$.Its extensive contents, various forms, participate in the students' goals, have permeability and radiation effects at the same time. School community can be roughly divided into the following six types, namely: "the theory of learning, academic research, science and technology innovative, voluntary service, cultural entertainment, integrated community." ${ }^{, 8]}$ These types of basic covers all aspects of university life, the activity of form is also varied. Each year freshmen reported are university club activities during the period of abundant period, shortly after the new students in the clubs should be through the rich and colorful form to absorb fresh blood. Both interests class and community volunteer service class, to join the students goal is roughly same, always want to learn from this type of club activities to something more. Through all kinds of activities in school, society must set up their position in the school, but also can conduct more campus cultural atmosphere to the freshman, make it have more understanding and recognition to the school.

\subsection{Student organizations play a role in the adaptive education for freshmen}

4.2.1. Is helpful to optimize the adaptability education environment

To carry out the adaptive education besides depends on specific teachers and students. Education environment is also very important. Marx said: "people create environment, also, the environment also create man." ${ }^{,[9]}$ Student community has an advantage by students self-management, can play a lot of activity form innovation. On the one hand shows the students' creativity and spirit, on the other hand also reflected a campus culture of the school. It will contact the campus culture in the form of a activities. Build a lively campus culture atmosphere. Make the adaptive education penetrated into all aspects of school life. Create a macro is easy to be accepted on campus cultural environment. For better adapt to the new school life play an important role. It is because there is such a harmonious and warm campus environment, in the process of increasing participation in various activities, implements the freshmen to school culture identity, to help freshmen better acceptance of campus culture, to complete the adaptive behavior.

4.2.2. Is advantageous to the rich freshmen adaptive education carrier.

Carrier can generally refers to energy or transport substance, knowledge or information as to form ${ }^{[10]}$ Diverse activities including in the university campus all aspects of student life, from theoretical study to hobbies, from innovative undertaking to voluntary services. We want to guide students to build the socialist requirement of world outlook, the outlook on life, values, and so on the positive energy of consciousness, have the intangible infiltrated the club activities. Many students are said by joining a club activities, to realize the importance of theory with practice. This suggests that the activities of education way more easily recognized and accepted by students. Will therefore adaptive education related content penetrating into the club activities, strengthen the student community, as well as the interaction between teachers and students exchange between through peer education and influence, make students develop new adaptability education and an important carrier. Student community is a new adaptive education carrier, with can't be matched by other carrier creative and active. Through the students constantly create, there are always new activities to attract new students to join in order to better adapt to the school, stability of their social roles.

4.2.3. Enhance the sustainability of the freshman adaptability education

The existence of the students in the school is not a temporary, but through successive students constantly live on and exist in the school for a long time. Although students are changing, but the club activities is not continuous. Compared with school at to carry out the adaptability of freshmen education lectures or theme class meeting. Student club activities with the characteristics of 
its sustainability continued to help freshmen adapt to school environment, school culture. Longer improves the adaptability of education, make its can more long time at work. In addition, participate in community college freshmen can from the society to realize many excellent senior students. For a freshman education guide is to help new students quickly adapt to the important part of the campus environment. Many freshmen at the beginning of the entrance is through some excellent senior student of peer education help them adapt to the new college life as soon as possible." In the education of college student's management, excellent senior college students can play the role of bridge and link. Excellent senior college students are more likely to become a college freshman friends, get their identity on the psychological and emotional. Help schools understand and master the information and dynamic of college freshmen, as well as to give information about the school freshman" ${ }^{[11]}$.This kind of communication with senior student learning is actually a kind of adaptive education inheritance and continuity.

\section{CONCLUSION}

To strengthen the adaptability of freshmen education school is an important way to help students to adapt to the school environment better and to merge the school of life, at the same time, it is also an important part of the work of students in a high level university students. Only to ensure that the students can keep the active learning and life attitude when the new semester begins can we make sure that they can develop and improve themselves better in the future life. At present, adaptive education for freshmen in Colleges and universities in our country is not perfect, the education content and the system is not so scientific, but if we do some related research and use the students organization to improve the adaptive education, its positive effect should be predictable. Student organizations have more advantages than the school administrative departments in communication with students, therefore, we must firmly grasp this advantage, and constantly improve the construction of school organization.

\section{References}

[1]Huang Xiting. Concise Dictionary of Psychology.[M]. He Fei: An Hui People's Publishing House,p348. 2004.

[2]Dwyer, J.O.A Historical Look at the Freshman Year Experience.Upcraft, M.L.\&Garder,J.L.The Freshman Year Experience. San Fransico: Jossey-Bass, p24-39. 1989.

[3][10]Zeng Ying.The Analysis of the Causes of College Students to Participate in the Community.[D]. Chongqing.Master thesis, southwest university.April 2007:p21.

[4]Kang Lifang. College Freshmen Adaptability Problem and Countermeasures to Huazhong Normal University Undergraduate Level 2010 Freshmen.[D].Shanghai.Huazhong Normal University master's thesis. In May 2012:p14.

[5]Guo Chunming. At Present Our Country College Students Adaptability Education the Main Problems and Countermeasures Research.[D]. Chongqing..Southwest university master's thesis.p25.p26.2012,

[6]the State Education Commission Student Management Department: College Students' Basic Knowledge of Management.[M]. Beijing: Beijing Normal University Press, 1991.

[7]Shen Xiaohua. Analysis on the Role of Student Associations in the University Ideological and political Education of College Students.[D]. Zheng Zhou: He Nan university, p6 2006(5).

[8]Marx, Engels. Marx and Engels anthology Volume 1.[M]. Beijing: People's Publishing House, p.92,1979.

[9]Li Yunchi, etc. Giving Full Play to the Advantages of Different Main Body, Strengthen the Adaptability Education of Freshmen.[J].Education theory and practice, p16,2012 (24). 